derivatives of every order, though, of course, included, are not made conspicuous. In fact, a teacher is a necessary accompaniment to the book, and a lone worker might flounder. Given a teacher who will guide, explain and help, the student will find the book a good and lively account of the subject.

The second part (chapters 10 to 18) continues chosen topies beyond the level of the first part. The density of exercises is less than in the first part and moreover greater maturity may be assumed in the reader. He will find the accounts of such subjects as subharmonic functions, Picard's theorem, the Riomann mapping theorem and Riemann surfaces an exhilarating study.

The book is very well printed and bound, and the price is reasonable.

J. C. BurkiLL

\section{FORCES BETWEEN MOLECULES}

\section{Intermolecular Forces}

Edited by Joseph O. Hirschfelder. (Advances in Chemical Physies, Vol. 12.) Pp. xi +643 . (Interscience (Wilcy): New York and London, 1967.) $210 s$.

Volume 12 of Advances in Chemical Physics is, like a number of precoding volumes, on one theme-in this instance intermolecular forces - -which has been the subject of much research activity in recent years. This volume contains ten chapters, all by authors who are acknowledged experts in their subject.

The first six chapters are devoted to advances in the theory and the remainder to experimental methods of determining intermolecular forces. The introductory chapter to the theoretical section by Hirschfoldor and Meath surveys the nature of intermolecular forces and illustrates the complexity of this subject by a very detailed analysis of the forces between two hydrogen atoms in their ground states. In the following chapters a number of more specialized topics are treated in detail. Buckingham discusses the interactions of simple molecules in terms of their electric multipole moments, permanent and induced. Dalgarno outlines the methods available for the calcula. tion of long range forces between atoms. The data for the coefficients of the leading term in the dispersion energy given in this chapter are perhaps the most impor. tant quantitative results of the theory of intermolecular forces obtained in recent years. Forces at very long range, where retardation effects are significant (>100 $\AA$ ), are treated by Power. Linder expounds the reaction field theory, well known in elcetrostatics, which can be extended to provide a very general interpretation of most features of long range intermolecular forces within one theoretical framework. Finally, in this section Sinanoglu tackles the formidable problems posed by the nonadditive behaviour of intermolecular forces in dense matter. The key to his approach is the definition of "effective pair potentials" in liquids in terms of two-body potentials estimated from gas phase studies and the refractive index of the liquid. Quantitative assessment of this procedure must await the determination of accurate two-body potentials.

The introductory chapter, by Mason and Monchick, to the experimental section of the book is a general review of both theoretical and experimental methods, and it is one of the areas of the book that should prove of most value to the non-specialist reader. The results obtained from low-energy beam seattering are summarized by Bernstein and Muckerman. This will provide a useful source of roference for workers in the field, though at the prosent time, with few exceptions, the beam results have not been of sufficient accuracy to shed new light on intermolecular forcos. Birnbaum discusses the use of microwave pressure broadening which can be used to study the interactions of anisotropic molecules and provides a useful method of estimating molecular quadrupole moments.
The scope of NMR in the study of intermolecular forces is surveyed by Bloom and Oppenheim in the final chapter of the book.

The cover asserts that "the reader will be impressed by the progress being made", and this is a fair statement of the position as far as the development of techniques and methods is concerned. Littlo progress has been made, however, in the quantitative description of the forces between molecules, and there is no modern substitute for the "Lennard-Jones parameters" which have been used with such zest and misplaced confidence by a generation of resoarch scientists.

This book is, in the editor's words, "intended to delve deeply and technically into recent advances", and much of its eontent is directed toward those who have some acquaintance with the subject. Selected portions, including the chapter already mentioned, will be of interest, however, to the non-specialist reader. E. B. Sмiтн

\section{SELENIUM SYSTEMS}

\section{Selenium and Selenides}

By D. M. Chizhikov and V. P. Shchastlivyi. 'Translated from the Russian by Eugene M. Elkin. Pp. xvi +403 . (Collet's (Publ.): London and Wellingborough, 1968.) 152s. $6 d$.

'THE unique physical properties of selenium and some of its binary selenides have long been exploited commercially, but the experimental techniques necessary to gain a full understanding of processes such as rectification and photoconductivity have only recently been developed and have not, as yet, been applied with rigour to selonium systems. On the other hand, new and careful X-ray studies have elucidated the nature of the many crystalline modifications and non-stoichiometric phases to be found among the selenides, and these results have now laid the basis for more detailed physical studies. It was at this juncture that the authors considered that a comprehensive collection of both the electrophysical and crystallographic data would be timely. All the known selenides of the main group, transition and rare earth elements are included and some 2,200 references to the original literature are given. A chapter devoted to bonding and structural types gives the necessary feel for the compounds.

A welcome emphasis has been placed on the preparation and handling of the high-purity samples demanded by modern electronic technology. Thus a chapter on the commercial retrieval of selenium lcads on to one about the production of high purity selenium, and finally to a section on the preparation of single crystals of selenium and the selenides.

The value of this reference work has justified its translation from the Russian and, because of the collection of data from both Western and Soviet sources, the usefulness of the English edition will not be impaired. The book should provide a basis for the further advance of the science of solenium and its solid state compounds.

N. N. Greenwood

\section{AMINO CHEMISTRY}

The Chemistry of the Amino Group

Edited by Saul Patai. (The Chemistry of Functional (Yroups.) $\mathrm{Pp}$ xiii +813 . (Interscience (Wiley) : London and New York, 1968.) $200 s$.

THIs is the fourth volume to appear under the editorship of Professor Saul Patai in this series of large monographs on the chemistry of individual functional groups. As with previous volumes, it has been necossary to go to press minus several promised chapters, in this case those on "Photochemistry of the Amino Group", "Syntheses 